http://jmscr.igmpublication.org/home/ ISSN (e)-2347-176x ISSN (p) 2455-0450 crossref DOI: https://dx.doi.org/10.18535/jmscr/v8i2.42

\title{
Effect of maternal hyperuricemia on post-spinal hypotension in preeclamptic parturients undergoing elective cesarean delivery: a prospective observational study
}

\author{
Authors \\ Sheikh Irshad Ahmad (Additional Professor), Syed Yusra Imtiyaz, \\ Shaista Yaqoob, Tantry Tariq Gani*
}

Department of Anaesthesiology and Critical Care, Sher-i-Kashmir Institute of Medical Sciences,

Soura, Srinagar, Jammu and Kashmir, India

*Corresponding Author

Tantry Tariq Gani

\begin{abstract}
Serum Uric acid (UA) is a marker of oxidative stress in preeclampsia. Hyperuricemia has been shown to be associated with impaired vascular relaxation in some retrospective studies. Elevated uric acid is also an independent predictor of hypertension. This study is designed to study the association between elevated serum uric acid levels and post spinal hypotension in pregnancy induced hypertension patients undergoing elective caesarean delivery under spinal anesthesia, as measured by requirement of vasopressors.

Materials and Methods: 204 patients with pregnancy induced hypertension scheduled for elective caesarean section under spinal anesthesia were included in the study. Demographic data, anesthetic management and peripartum course were recorded. Serum uric levels were measured on arrival to operation theatre. Doses of vasopressor agents required after spinal anesthesia was recorded. The association between serum uric acid level and requirement of vasopressor was studied. Data was analysed using students t test and chisquare test. $P$-value $<0.05$ was considered significant.

Results and Observations: Requirement of vasopressors was lower in patients with high serum uric acid levels than those with lower serum uric acid levels. Results were similar with both phenylephrine and ephedrine. The difference in vasopressor requirement was statistically significant.(p-value $<0.05)$

Conclusion: Elevated serum uric acid levels are inversely related to development of post spinal hypotension and requirement of vasopressors in preeclamptic patients undergoing cesarean section under spinal anesthesia.

Keywords: Serum uric acid, Post spinal hypotension, Preeclampsia, Vasopressors.
\end{abstract}

\section{Introduction}

Pregnancy is a physiological stress in which many changes occur in the milieu interior of the body, more and more stress is being laid on the biochemical changes, which occur in the blood during normal pregnancy becomes exaggerated in complications of pregnancy like pre-eclampsia. ${ }^{[1]}$ Oxidative stress increases during pre-eclampsia and results in increased production of lipid peroxides, reactive oxygen species and superoxide anion radicals to cause endothelial injury and dysfunction, platelet and neutrophil activation ${ }^{[2-3]}$. 
Uric acid (UA) is a marker of oxidative stress. Recent retrospective reports have associated hyperuricemia with decrease in vascular relaxation. Association between elevated serum uric acid (UA) and preeclampsia has been attributed to renal dysfunction and the degradation of purines from maternal, fetal or placental tissues Increasing evidence suggests that the rise in uric acid in pre-eclampsia is not merely a nonspecific reflection of kidney damage, but a sign of antioxidative response, possibly related to the pathogenesis of pre-eclampsia ${ }^{[4]}$. The enzyme responsible for metabolizing purines to $\mathrm{UA}$ is xanthine oxidase/dehydrogenase (XO), which produces reactive oxygen species (ROS), such as superoxide and hydrogen peroxide, as by-products. Oxidative stress is considered an essential contributor to the development and maintenance of preeclampsia, ${ }^{[5]}$ and serum UA has subsequently been proposed as an appropriate marker for the severity of this stress ${ }^{[6,7]}$. An elevated UA has been observed to be an independent predictor for the development of hypertension. ${ }^{[8,9]}$ During pregnancy, oxidative stress may be responsible for the impaired relaxation of vascular smooth muscle that results in hypertension, a signature feature of preeclampsia. $^{[10]}$ The hypertension associated with preeclampsia can exhibit significant resistance to multimodal antihypertensive therapy; even the administration of spinal anaesthesia results in less hypotension in preeclamptic than in healthy parturients. ${ }^{[11]}$ Based on these observations, we devised this study to study the association between elevated serum uric acid levels and post spinal hypotension in pregnancy induced hypertension patients undergoing caesarean delivery under spinal anaesthesia.

\section{Materials and Methods}

This prospective observational clinical study was conducted in Sheri Kashmir Institute of medical sciences, kashmir, India from September 2017 to August 2019. The study was conducted after approval by the Institutional Ethical Committee and an informed written consent was obtained from all the patients for participation in this study. Preanaesthetic evaluation was done for all patients participating in this study. A total of 200 patients with documented pregnancy induced hypertension were enrolled for the study.

Patients with the following parameters were excluded from the study:

Patient refusal

Raised intracranialtension

Bleeding disorders or anticoagulation therapy 4.Infection at local site

Hypersensitivity to drugs given to these patients

Deformity of lumbarspine

Hyperuricemic patients

Patients on drug therapy for hyperuricemia

Uncontrolled BP at the time of study

End organ damage secondary to PIH

Preeclampsia or eclampsia at the time of study

Patients requiring general anesthesia for LSCS

Patients not having properly maintained antenatal medical records

All the patients were premedicated with oral ranitidine $150 \mathrm{mg}$ a night before surgery. On arrival to operation theatre, intravenous cannula was secured and blood sample for estimation of serum uric acid level was taken from all the patients. Standard anaesthetic monitoring viz electrocardiogram, non invasive blood pressure, pulse oximetry shall be instituted before taking the sample. All the baseline parameters (heart rate, blood pressure and oxygen saturation) will be recorded prior to spinal anesthesia and at 5 minute intervals till the end of surgery. All the patients will be preloaded with lactated ringers solution 10 $\mathrm{ml} / \mathrm{kg}$ bodyweight prior to spinal anaesthesia. The procedure will be carried out in lateral decubitus or sitting position with 27 gauge spinal needle. Proper position of spinal needle in sub-arachnoid space will be confirmed by free flow of cerebrospinal fluid. Heavy Bupivacaine $12.5 \mathrm{mg}(2.5 \mathrm{ml})$ with fentanyl $25 \mathrm{mcg}(0.5 \mathrm{ml})$ was administered into the subarachnoid space (total $3 \mathrm{ml}$ ).

Sensory block was checked with response to ice 
packs with target highest sensory

level to be achieved at T4 level.

Motor blockade: This will be assessed by Modified Bromage Scale' as under:

Grade 0: No Paralysis.

Grade 1: Unable to raise extended leg against gravity but able to flex knee. Grade 2: unable to flex knees but able to flex ankle.

Grade 3: unable to flex ankle and foot.

Surgery was started after confirmation of sensory block and motor block. Injection oxytocin 5U i.v. bolus followed by $15 \mathrm{U}$ continuous infusion in normal saline at the rate of $5 \mathrm{u} / \mathrm{h}$ was given to all patients. Additional oxytocin and prostaglandin E1 were given as rescue uterotonic drugs in case of inadequate uterine contraction with intial dose of oxytocin in both groups. Injection methyl ergotomine as uterotonic drug was strictly avoided in all patients.

Hypotension was defined as drop of more than $20 \%$ in basal mean arterial blood pressure or systolic blood pressure less than $100 \mathrm{mmHg}$ or diastolic blood pressure less than $60 \mathrm{~mm} \mathrm{Hg}$. Hypotension was treated with bolus doses of injection ephedrine 6 miligrams in patients with heart rate of less than $60 \mathrm{bpm}$ and with injection phenylepherine bolus doses of $50 \mathrm{mcg}$ in patients with heart rate more than $100 \mathrm{bpm}$ respectively. Total dose of vasopressor agents required and the total number of doses of vasopressor agents required in each patient were recorded for statistical analysis. Oxygen supplementation was provided in case of respiratory depression that is $\mathrm{SPO} 2<90 \%$ and respiratory rate $<8$.

Collection of blood sample and administration of vasopressor agents was performed by an anesthesiologist not participating in the study. These were in coded form that were decoded at the end of study. Any untoward incident or side effect like nausea, vomiting, hypotension, respiratory depression, drowsiness, etc. were recorded.

All statistical analysis was done using SPSS software. Discrete variables will be expressed as counts i.e as percentage (\%), and continuous variables as mean $+/-$ standard deviation.
Analysis was done using student t-test and $\mathrm{p}$ value of less than 0.05 was considered significant.

\section{Results and Observations}

A total of 204 patients with documented pregnancy induced hypertension scheduled for elective cesarean section under spinal anaesthesia were enrolled for the study. Minimum age and maximum age of 20 years (16) and 35 years (16) respectively most of the patients (80) enrolled in the study were observed in the age group 28-30 years. of the 204 enrolled PIH patients in the study 120 (58.8\%) patients had significantly higher serum uric acid levels (>5.7).

Out of the 204 enrolled patients in the study, 140 patients had a mean serum uric acid level of $6.3 \mathrm{mg} / \mathrm{dl}$ and they didn't require any dose of ephedrine whereas 64 patients with an average serum uric acid level of $4.9 \mathrm{mg} / \mathrm{dl}$ required $1-2$ doses of ephedrine. 48 patients who required one dose of ephedrine has a mean serum uric acid level of $4.655 \mathrm{mg} / \mathrm{dl}$. The difference in serum uric acid level was statistically highly significant when compared to patients who did not require any ephedrine ( $p$ - value $<0.001$ ). Serum uric acid was also lower in patients who received two doses of ephedrine than those who did not require any ephedrine $(5.725 \mathrm{mg} / \mathrm{dl} \quad$ vs $6.368 \mathrm{mg} / \mathrm{dl}$ respectively). However the difference was not statistically significant ( $p$-value 0.063 ). It was also observed that of the 204 enrolled patients 124 patients with an average serum uric acid level of 6.8 didn't require any dose of phenyepherine, whereas 80 patients with an average serum uric acid level 4.5 required 1-3 doses of phenylepherine. The difference was statistically significant ( $\mathrm{p}$ value $<0.001$ )

Out of the 204 enrolled patients 124 patients with an average serum uric acid

level of $6.8 \mathrm{mg} / \mathrm{dl}$ didn't require any dose of phenyepherine whereas 80 patients with an average serum uric acid level $4.5 \mathrm{mg} / \mathrm{dl}$ required 1-3 doses of phenylepherine. 40 patients who required only one dose of phenylephrine has a mean serum uric acid level of $4.65 \mathrm{mg} / \mathrm{dl}$. The difference was 
statistically significant when compared to patients who did not require phenylephrine (pvalue $<0.001)$. 16 patients requiring two doses of phenylephrine had a mean serum uric acid level of $4.725 \mathrm{mg} / \mathrm{dl}$ which was lower than those patients who did not require any dose of phenylephrine. Again the difference was statistically significant (p-value 0.001).24 patients who required 3 doses of phenylephrine also had mean serum uric acid levels lower than those who did not require phenylephrine $\quad(4.066 \mathrm{mg} / \mathrm{dl}$ vs $6.833 \mathrm{mg} / \mathrm{dl}$ respectively). The difference was statistically highly significant. ( $p$ - value $<0.001$.

Table 1: Showing Age distribution of patients taken for the study

\begin{tabular}{|c|c|c|}
\hline Age & Frequency & Percent \\
\hline 20 & 16 & 7.8 \\
\hline 22 & 16 & 7.8 \\
\hline 24 & 8 & 3.9 \\
\hline 25 & 20 & 9.8 \\
\hline 26 & 8 & 3.9 \\
\hline 28 & 24 & 11.8 \\
\hline 29 & 40 & 19.6 \\
\hline 30 & 16 & 7.8 \\
\hline 31 & 16 & 7.8 \\
\hline 32 & 24 & 11.8 \\
\hline 35 & 16 & 7.8 \\
\hline Total & $\mathbf{2 0 4}$ & $\mathbf{1 0 0 . 0}$ \\
\hline
\end{tabular}

Table 2: Showing the number of PIH patients on medication

\begin{tabular}{|c|c|c|}
\hline DRUG & FREQUENCY & PERCENT \\
\hline LABETALOL & 164 & 80.4 \\
100 & & \\
NIL & 40 & 19.6 \\
Total & 204 & 100.0 \\
\hline
\end{tabular}

Table 3: Showing the serum uric acid ( $\mathrm{mg} / \mathrm{dl})$ correlation with pregnancy induced hypertension

\begin{tabular}{|l|c|c|}
\hline SERUM URIC ACID $(\mathrm{mg} / \mathrm{dl})$ & FREQUENCY & PERCENT \\
\hline$<=5.7$ & 84 & 41.2 \\
\hline$>5.7$ & 120 & 58.8 \\
\hline Total & 204 & 100.0 \\
\hline
\end{tabular}

Table 4: Showing the relation between level of Serum Uric Acid andEphedrine in PIH patients undergoing caesarian under spinal anesthesia.

\begin{tabular}{|ll|c|c|c|c|}
\hline EPHEDRINE & & $\mathrm{N}$ & Mean & $\begin{array}{c}\text { Std. } \\
\text { Deviation }\end{array}$ & P value \\
\hline SERUM URIC ACID & No & 140 & 6.3680 & 1.69435 & \\
$(\mathrm{mg} / \mathrm{dl})$ & Yes & 64 & 4.9225 & 1.52683 & $<0.001$ \\
\hline
\end{tabular}


Table 5: Showing the relation between level of Serum Uric Acid and dose of Ephedrine in PIH patients undergoing caesarian under spinal anesthesia.

\begin{tabular}{|c|c|c|c|c|c|c|c|c|}
\hline \multirow[b]{2}{*}{ EPHEDRINE } & \multirow[b]{2}{*}{$\mathrm{N}$} & \multirow[b]{2}{*}{ Mean } & \multirow[b]{2}{*}{$\begin{array}{c}\text { Std. } \\
\text { Deviatio } \mathrm{n}\end{array}$} & \multicolumn{2}{|c|}{$\begin{array}{c}95 \% \\
\begin{array}{c}\text { Confidence Interval for } \\
\text { Mean }\end{array}\end{array}$} & \multirow[b]{2}{*}{ Minimu $\mathrm{m}$} & \multirow[b]{2}{*}{ Maxi mum } & \multirow[b]{2}{*}{$\mathrm{P}$-value } \\
\hline & & & & $\begin{array}{c}\text { Lower Boun } \\
\mathrm{d}\end{array}$ & $\begin{array}{l}\text { Upper } \\
\text { Bound }\end{array}$ & & & \\
\hline No dose & $\begin{array}{c}14 \\
0\end{array}$ & 6.368 & 1.69435 & $\begin{array}{c}6.084 \\
9\end{array}$ & $\begin{array}{c}6.651 \\
1\end{array}$ & 2.70 & 8.20 & \\
\hline 1 dose & 48 & 4.655 & 1.54133 & $\begin{array}{c}4.207 \\
4\end{array}$ & $\begin{array}{c}5.102 \\
6\end{array}$ & 2.60 & 7.90 & $<0.001$ \\
\hline 2 doses & 16 & 5.725 & 1.19638 & $\begin{array}{c}5.087 \\
5\end{array}$ & $\begin{array}{c}6.362 \\
5\end{array}$ & 4.90 & 7.70 & 0.063 \\
\hline Total & $\begin{array}{c}20 \\
4 \\
\end{array}$ & 5.914 & 1.77237 & $\begin{array}{c}5.669 \\
8\end{array}$ & $\begin{array}{c}6.159 \\
2 \\
\end{array}$ & 2.60 & 8.20 & \\
\hline
\end{tabular}

Table 6: Showing the relation between level of Serum Uric Acid and Phenylephrine in PIH patients undergoing caesarian under spinal anesthesia.

\begin{tabular}{|ll|c|c|c|c|}
\hline PHENYLEPHRINE & & No. & Mean & $\begin{array}{c}\text { Std. } \\
\text { Deviation }\end{array}$ & $\begin{array}{c}\text { P } \\
\text { Value }\end{array}$ \\
\hline SERUM URIC ACID & No & 124 & 6.8335 & 1.17391 & \\
$(\mathrm{mg} / \mathrm{dl})$ & Yes & 80 & 4.4900 & 1.59553 & $<0.001$ \\
\hline
\end{tabular}

Table 7: Showing the relation between level of Serum Uric Acid and dose of Phenylephrine in PIH patients undergoing caesarian under spinal anesthesia

\begin{tabular}{|c|c|c|c|c|c|c|c|c|}
\hline \multirow[b]{2}{*}{ PHENYLEPHRINE } & \multirow[b]{2}{*}{$\mathrm{N}$} & \multirow[b]{2}{*}{ Mean } & \multirow[b]{2}{*}{ Std. Devia tion } & \multicolumn{2}{|c|}{$\begin{array}{c}95 \% \\
\text { Confidence Interval for Mean }\end{array}$} & \multirow[b]{2}{*}{$\underset{\mathrm{m}}{\operatorname{Minimu}}$} & \multirow[b]{2}{*}{ Maxi mum } & \multirow[b]{2}{*}{$\mathrm{P}$ value } \\
\hline & & & & $\begin{array}{c}\text { Lower Boun } \\
\mathrm{d}\end{array}$ & $\begin{array}{l}\text { Upper } \\
\text { Bound }\end{array}$ & & & \\
\hline $\begin{array}{l}\text { No } \\
\text { dose } \\
\text { doses } \\
\text { doses Total }\end{array}$ & $\begin{array}{c}124 \\
40 \\
16 \\
24 \\
204\end{array}$ & $\begin{array}{l}6.833 \\
4.650 \\
4.725 \\
4.066 \\
5.914\end{array}$ & $\begin{array}{l}1.174 \\
1.821 \\
2.063 \\
0.268 \\
1.772\end{array}$ & $\begin{array}{l}6.624 \\
4.067 \\
3.625 \\
3.953 \\
5.669\end{array}$ & $\begin{array}{l}7.0422 \\
5.2325 \\
5.8246 \\
4.1799 \\
6.1592\end{array}$ & $\begin{array}{l}4.10 \\
2.60 \\
2.90 \\
3.70 \\
2.60\end{array}$ & $\begin{array}{l}8.20 \\
7.90 \\
7.70 \\
4.30 \\
8.20\end{array}$ & $\begin{array}{c}<0.001 \\
0.001 \\
<0.001\end{array}$ \\
\hline
\end{tabular}

Table 8: Showing frequency of side effects

\begin{tabular}{|l|c|c|c|}
\hline SIDE EFFECT & PRESENT & NUMBER & PERCENTAGE \\
\hline \multirow{3}{*}{ HYPOTENSION } & YES & 88 & 43.1 \\
\cline { 2 - 4 } & NO & 116 & 56.9 \\
\hline \multirow{3}{*}{ NAUSEA } & YES & 16 & 7.8 \\
\hline \multirow{3}{*}{ VOMITING } & NO & 188 & 92.2 \\
\hline \multirow{3}{*}{ BRADYCARDIA } & YES & 0 & 0 \\
\cline { 2 - 4 } & NO & 204 & 100 \\
\cline { 2 - 4 } & YES & 8 & 3.9 \\
\hline
\end{tabular}

\section{Discussion}

In our study we observed that an elevated serum uric acid level in pregnancy induced hypertension patients undergoing cesarean delivery under spinal anaesthesia was associated with lower vasopressor use. These findings are consistent with the observation that the incidence of spinal anesthesia-induced hypotension during pregnancy is significantly lower in patients with severe preeclampsia when compared to healthy, normotensive women. ${ }^{[11,12]}$ A prospective cohort study controlling for neonatal weight, observed a 
significantly lower incidence of hypotension $(24.4 \%$ vs. $40.8 \%$, ) and vasopressor requirements (ephedrine $9.8 \pm$ vs. $15.8 \pm 6.2 \mathrm{mg}$ ) after spinal anesthesia for cesarean delivery in patients with severe preeclampsia compared to healthy parturients. ${ }^{[11]}$ These results were confirmed in another study where the range in vasopressor use, when converted into phenylephrine equivalents, similar to our study. ${ }^{13}$

The mechanism by which an elevation in serum UA can serve as a marker for hypertension appears to be related to the synthesis of endothelial nitric oxide. ${ }^{[14,15]}$ The addition of plasma from women with preeclampsia to biopsy samples from women without preeclampsia can inhibit normal uterine vasorelaxation. ${ }^{[16]}$ The resulting vasoconstriction is reversed with the normalization of serum UA. ${ }^{[17]}$ Allopurinol, a XO inhibitor which leads to a reduction in serum UA, has been used successfully in the treatment of hypertension. ${ }^{[18]} \mathrm{By}$ contrast, a small study found no correlation between serum UA levels and vessel relaxation or the effect of plasma from preeclamptic patients on in vitro endothelial function, however, this study was likely underpowered. ${ }^{[19]}$ Hypertensive parturients have elevated concentrations of circulating vasopressors, such as thromboxane and endothelin, with parallel decreases in vasodilators such as prostacyclin. ${ }^{[20,21]}$ The maternal vasculature of hypertensive parturients also exhibits increased sensitivity to pressor agents. ${ }^{[22]}$ It is proposed that this is in part due to reduced availability of nitric oxide secondary to the endothelial dysfunction. ${ }^{[23]}$ Elevated uric acid concentration could participate in reduced production of nitric oxide (NO) and may in part explain the altered endothelial contribution to vascular tone in hypertensive parturients.

A trend towards lower vasopressor use after spinal anaesthesia was observed with increasing serum uric acid. The results were similar with both ephedrine and phenylephrine. Our results are similar to study done by Kochapava et al ${ }^{[24]}$ who studied the relation between elevated serum uric acid level and vasopressor use in patients undergoing neuraxial anaesthesia for caesarean delivery and found that elevated serum uric acid in parturients is associated with decreased use of post spinalvasopressors. ${ }^{[24]}$

The results of our study are also the same as the study conducted by Bhatia $\mathrm{N}$ et al. ${ }^{[25]}$ They studied the effect of maternal hyperuricemia on postspinal hypotension in normotensive parturients undergoing non elective caesarean delivery in a prospective observational study and observed that elevated serum uric acid levels were associated with lower incidence of post spinal hypotension and reduced need of vasopressors to maintain blood pressure within a normal range. ${ }^{[25]}$

\section{Limitations}

Serum UA levels can increase with food intake, which was not controlled in our study. The serum UA levels obtained in the postoperative period may be influenced by the dilutional effects of intravenous fluids administered during the cesarean delivery or by resolution of the hypertensive disorder. To avoid this, all samples were taken preoperatively before instituting fluid loading.

\section{Conclusion}

Elevated serum uric acid levels were inversely related to development of hypotension and requirement of vasopressor to maintain blood pressure within normal range in preeclamptic parturients undergoing spinal anesthesia for caesarean delivery. From the study, we conclude that serum uric levels are increased in patients with pregnancy induced hypertension, and in addition to serve as a marker of disease elevated serum can predict the development of hypotension after spinal anesthesia for elective caesarean section in such patients.

\section{References}

1. Kashinakunti SV, Sunitha H, Gurupadappa K, Shankarprasad DS, Suryaprakash G and Ingin JB. Lipid Peroxidation and Antioxidant Status in Preeclampsia. Al 
Ameen J Med Sci 2010;3 (1) :38-41.

2. Dutta DC, Konar HL, Test Book of Obstetrics, 6th edn. New Central Book Agency (P) Ltd. 2004,pp222-223.

3. Riza Madazli, Ali Benian, Koray Gumata et al. Lipid peroxidation and antioxidants inpre Eclampsia. Eur J Obstet Gynecol \& Reprod Biol 1999; 85 (2): 205208.

4. Utoila JT, Tuimala RJ, Aarnio TM, Pyykko KA, Ahotupa MO. Findings on lipid peroxidation and antioxidant function in hypertensive complications of pregnancy. Br J Obstet Gynecol 1993:100: 270-276.

5. Powers RW, Bodnar LM, Ness RB, et al. Uric acid concentrations in early pregnancy among preeclamptic women with gestational hyperuricemia at delivery. Am J Obstet Gynecol 2006; 194:160 e 1—8.

6. Yildirim A, Altinkaynak $\mathrm{K}$, Aksoy $\mathrm{H}$, Sahin YN, Akcay F. Plasma xanthine oxidase, superoxide dismutase and glutathione peroxidase activities and uric acid levels in severe and mild preeclampsia. Cell Biochem Funct 2004;22:213-7.

7. Many A, Hubel CA, Roberts JM. Hyperuricemia and xanthine oxidase in preeclampsia, revisited. Am J Obstet Gynecol 1996;174:288-91

8. Sundstrom J, Sullivan L, D'Agostino RB, Levy D, Kannel WB, Vasan RS. Relations of serum uric acid to longitudinal blood pressure tracking and hypertension incidence. Hypertension 2005;45:28-33.

9. Perlstein TS, Gumieniak O, Williams GH, et al. Uric acid and the development of hypertension: the normative aging study. Hypertension 2006;48:1031-6.

10. Parrish MR, Wallace K, Tam Tam KB, et al. Hypertension in response to AT1- AA: role of reactive oxygen species in pregnancyinduced hypertension. Am J Hypertens 2011;24:835—40.
11. Aya AG, Vialles N, Tanoubi I, et al. Spinal anesthesia-induced hypotension: a risk comparison between patients with severe preeclampsia and healthy women undergoing preterm caesarean delivery. Anesth Analg 2005;101:869-75.

12. Aya AG, Mangin $R$, Vialles $N$, et al. Patients with severe preeclampsia experience less hypotension during spinal anesthesia for elective cesarean delivery than healthy parturients: a prospective cohort comparison. Anesth Analg 2003;97:867-72.

13. Clark VA, Sharwood-Smith GH, Stewart AV. Ephedrine requirements are reduced during spinal anaesthesia for caesarean section in preeclampsia. Int $\mathbf{J}$ Obstet Anesth 2005;14:9-13.

14. Saavedra WF, Paolocci N, St John ME, et al. Imbalance between xanthine oxidase and nitric oxide synthase signaling pathways underlies mechanoenergetic uncoupling in the failing heart. Circ Res 2002;90:297-304.

15. Cappola TP, Kass DA, Nelson GS, et al. Allopurinol improves myocardial efficiency in patients with idiopathic dilated cardiomyopathy. Circulation 2001;104:2407-11.

16. Hayman R, Warren A, Brockelsby J, Johnson I, Baker P. Plasma from women with pre-eclampsia induces an in vitro alteration inthe endothelium-dependent behaviour of myometrial resistance arteries. BJOG 2000;107:108-15.

17. Khosla UM, Zharikov S, Finch JL, et al. Hyperuricemia induces endothelial dysfunction. Kidney Int 2005;67:1739—42.

18. Feig DI, Soletsky B, Johnson RJ. Effect of allopurinol on blood pressure of adolescents with newly diagnosed essential hypertension: a randomized trial. JAMA 2008;300:924-32.

19. Jewsbury S, Sheikh N, Crocker I, Baker PN, Myers JE. Plasma uric acid levels do 
not correlate to plasma-evoked changes in endothelial function in women with preeclampsia. Eur J Obstet Gynecol Reprod Biol 2008;137:118-9.

20. Taylor RN, Varma M, Teng NN, Roberts JM. Women with preeclampsia have higher plasma endothelin levels than women with normal pregnancies. J Clin Endocrinol Metab. 1990 Dec; 71:1675-7.

21. Walsh SW. Eicosanoids in preeclampsia. Prostaglandins Leukot Essent Fatty Acids. 2004Feb; 70(2):223-32.

22. Vedernikov Y, Saade GR, Garfield RE. Vascular reactivity in preeclampsia. Semin Perinatol. 1999 Feb; 23(1):34- 44.

23. Roberts JM, Taylor RN, Musci TJ, Rodgers GM, Hubel CA, Mclaughlin MK. Pre- eclampsia: an endothelial cell disorder. Am J Obstet Gynecol. 1989 Nov; 161(5):1200-4.

24. V.P. Kovacheva, M.A. Soens, L.C. Tsen. Serum uric acid as a novel marker for uterine atony and post-spinal vasopressor use during cesarean delivery. International Journal of Obstetric Anesthesia (2013) 22, 200-208

25. Bhatia N, Jain K, Sikka P, Verma I. Effect of maternal hyperuricemia on post- spinal hypotension and uterine tone in normotensive parturients undergoing nonelective cesarean delivery: a prospective observational study. Anesthesia \& Analgesia. 2016 Sep;123(3S-suppl):235. 